\title{
Improvement of functional bloating by an enterovaccine: a preliminary study
}

\author{
M. Grassini, E. Battaglia, C. Verna, P. Niola, A. Repici ${ }^{1}$, N. Corazzi ${ }^{2}$ and G. Bassotti ${ }^{2}$ \\ Gastroenterology Section. Cardinal Massaja Hospital. Asti, Italy. ${ }^{I}$ Gastroenterology Unit. Humanitas Institute. Rozzano, \\ Milano; and ${ }^{2}$ Gastroenterology and Hepatology Section. Department of Clinical and Experimental Medicine. University \\ of Perugia. Perugia, Italy
}

\begin{abstract}
Background: bloating is a fastidious symptom reported by many patients who also have other gastrointestinal functional disorders. Bloating is more common in women, and it is often associated with meals and improves or disappears overnight. No specific treatments are to date available for this disturbing symptom.

Aims: to evaluate the effects of an oral enterovaccine (Colifagina ${ }^{\circledR}$ ) on bloating and other abdominal symptoms in patients with prevalent complaints of functional bloating.

Patients and methods: one hundred and forty-eight patients with functional bloating according to Rome III criteria were recruited. Questionnaires and a VAS scale on their symptoms were administered at baseline and after four weeks of therapy with Colifagina ${ }^{\circledR}$.

Results: after treatment, a significant amelioration of bloating ( $p<0.0001)$, abdominal pain $(p<0.0001)$ and flatus $(p<$ 0.0001 ) was observed; nausea and vomiting scores were not significantly different at the end of the treatment. Subjective wellbeing was also generally improved $(p<0.001)$ in treated patients.

Conclusion: treatment with an enterovaccine may help improve symptoms in patients with functional bloating.
\end{abstract}

Key words: Bloating. Enterovaccine. Functional disorder.

\section{INTRODUCTION}

Bloating is a fastidious symptom reported by up to $96 \%$ patients who also have another gastrointestinal functional disorder, such as patients with irritable bowel

Received: 18-03-09.

Accepted: 12-05-09.

Correspondence: Gabrio Bassotti. Clinica di Gastroenterologia ed Epatologia. Ospedale Santa Maria della Misericordia. Piazzale Menghini, 1. 06156 San Sisto (Perugia) Italy.e-mail: gabassot@tin.it
M. Grassini, E. Battaglia, C. Verna, P. Niola, A. Repici, N. Corazzi and $G$. Bassotti. Improvement of functional bloating by an enterovaccine: a preliminary study. Rev Esp Enferm Dig 2009; 101: 619-622.

syndrome (IBS). More common in women, it is often associated with meals and improves or disappears overnight $(1,2)$. In community observational studies 10 $30 \%$ of subjects reported bloating during the previous year $(3,4)$.

According to Rome III criteria functional bloating (FB) is defined as a recurrent sensation of abdominal distension that may or may not be associated with measurable distension, but is not part of another functional bowel or gastroduodenal disorder $(5,6)$.

The treatment of bloating is similar whether it appears as an isolated symptom or associated with another functional disorder. Most treatments are designed to reduce gas, but this measure is yet of unproven efficacy (7).

Recently, it has been shown that the administration of an oral enterovaccine $\left(\right.$ Colifagina ${ }^{\oplus}$, polymicrobial lysate of gram-negative enterobacteriaceae) was an effective immunostimulant in improving a model of murine colitis; moreover, it significantly increased the fecal concentration of $\operatorname{Ig} \mathrm{A}$ in healthy and colitic mice (8). In addition, in a previous study in patients with colonic diverticular disease, this enterovaccine improved symptoms and prevented their recurrence, particularly bloating, probably due to a direct stimulation of IgA-mediated mucosal modulation (9). This immune activation has been widely emphasized in various unifying pathophysiological models to explain gastrointestinal functional disorders, like FB (10).

On the above basis, in the present study we assessed abdominal symptoms in a population of patients with FB treated with an oral enterovaccine (Colifagina $\left.{ }^{\circledR}\right)$. 


\section{PATIENTS AND METHODS}

This was an observational uncontrolled prospective study on unselected outpatients referred for gastroenterological evaluation.

In a six-month period we recruited 148 patients $(45 \mathrm{M} / 103 \mathrm{~F}$, mean age 41.96 yrs, range 18-64, median 41 yrs) with FB according to Rome III criteria (5). None of the subjects took antibiotics or immunosoppressive agents, or any medication that could alter digestive motility, gut microenvironment or bowel immunity in the two weeks preceding the study, nor during the study period. Mechanical obstruction or other GI diseases were excluded by endoscopy and abdominal ultrasound examination.

None of the patients had previously undergone abdominal surgery, except appendectomy, or had abdominal symptoms or a history of upper gastrointestinal disorders. Patients with psychiatric disorders, cardiovascular, kidney or neoplastic disease were excluded from the study. Also, no patient fulfilled the criteria for irritable bowel syndrome (IBS) (5).

All patients were evaluated before (visit 1) and after four weeks of therapy with Colifagina ${ }^{\circledR}$ (ABC Farmaceutici, Ivrea, Italy), 1 ampoule per os b.id. (visit 2). Colifagina $^{\circledR}$ contains lysate of $8.0 \times 10^{7}$ Escherichia coli O1,O2,O55,O111; $5.0 \times 10^{7}$ Bacillus pumilus, $4.0 \times 10^{7}$ Alcaligenes faecalis, Shigella faecalis, Bacillus subtilis, Proteus vulgaris. After mixing the strains, the compound is immediately exposed to heat and pressure (via autoclave), and is sterile thereafter.

By means of a medical interview patients were questioned about nausea, vomiting, bloating, abdominal pain, flatus and wellbeing; all symptoms were scored using a visual analogical scale (VAS; score $0=$ absent $-10=$ serious); wellbeing was scored by a visual analogical scale (VAS) $0=$ I feel very well $10=$ I feel very bad; stool shape was estimated using Bristol's scale stool form classification (11).

The study was carried out according to local ethical rules, after receiving the patients' written informed consent, and in accordance with the recommendations of the Helsinki Declaration (Edinburgh revision, 2000).

\section{Statistical analysis}

Data were analyzed by means of the Wilcoxon's signed rank test. Values of $p<0.05$ were chosen for rejection of the null hypothesis. Data are presented as mean $\pm \mathrm{SD}$.

\section{RESULTS}

Overall, 112/148 (76\%) patients (38 men, 74 women, mean age 43 yrs, range 18-64) completed the study; the 36 drop-outs ( 7 men, 29 women, mean age 39 yrs, range
23-59) were due to an early suspension of the compound due to immediate (within a week) lack of efficacy (22 cases) and reduced bowel frequency during the study (14 cases), also leading to an interruption of the schedule.

None of the 121 patients who completed the study showed any drug-related side or adverse effects.

The effects of Colifagina ${ }^{\circledast}$ administration on bloating, abdominal pain, flatus, nausea, vomiting and wellbeing, as scored by VAS, are synthesized in table I and shown in figure 1. A significant amelioration of bloating $(\mathrm{p}<0.0001)$, abdominal pain $(\mathrm{p}<0.0001)$ and flatus $(\mathrm{p}<0.0001)$ was observed, but nausea and vomiting scores were not significantly different at the end of treatment. Subjective wellbeing was also generally improved $(\mathrm{p}<0.001)$ in treated patients. The stool shape was modified by therapy, with a shift from type 4 to type 2 (increased consistency) in Bristol's classification at the end of the treatment period.

Table I. Results of VAS symptom score, expressed as mean $\pm S D$

\begin{tabular}{lccc}
\hline & Pre-therapy & Post-therapy & Significance \\
\hline Bloating & $6.40 \pm 2.36$ & $2.3 \pm 1.98$ & $\mathrm{p}<0.0001$ \\
Pain & $2.93 \pm 1.91$ & $0.95 \pm 1.34$ & $\mathrm{p}<0.0001$ \\
Flatus & $7.6 \pm 2.15$ & $2.22 \pm 1.9$ & $\mathrm{p}<0.0001$ \\
Nausea & $1.2 \pm 1.37$ & $0.66 \pm 1.15$ & n.s. \\
Vomiting & $0.12 \pm 0.32$ & $0.02 \pm 0.13$ & n.s. \\
Well-being & $7.88 \pm 1.64$ & $3.58 \pm 2.52$ & $\mathrm{p}<0.001$ \\
\hline
\end{tabular}

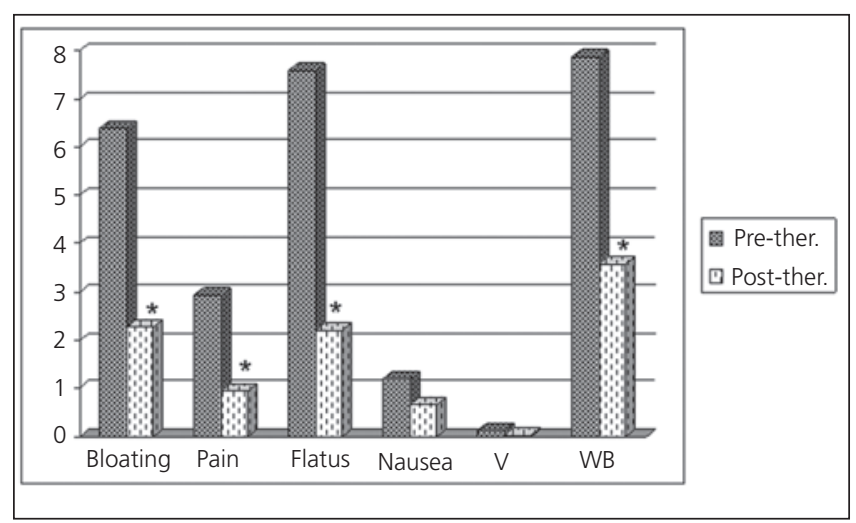

Fig. 1. Pre- and post-therapy VAS score. Results are expressed as mean. $*=p<0.001$ vs. pre-therapy.

\section{DISCUSSION}

Functional bloating is an unpleasant symptom in otherwise healthy adults, but no firm therapeutic strategies have been defined. Although most treatments aim at reducing intestinal gas, their efficacy is presently unproven (9). The recent reports on the potential pathogenetic roles of the enteric flora and immune activation in functional gastrointestinal disorders (especially IBS) (12) have led 
to a reawakened interest in bacteriotherapy for this common and challenging disorder.

Some evidence on the efficacy of probiotics to treat individual symptoms such as diarrhea, constipation, and bloating (13-15) exists, using bacterial monospecies as nutraceutic (13) or functional food (15). Moreover, probiotic monospecies treatment of IBS patients has also been shown to have beneficial effects on abdominal pain and stool frequency normalization (16), as well as to improve orocecal transit, colonic transit, abdominal distension, and constipation in women with constipation-predominant IBS (17).

However, it should be taken into account that the interpretation of the literature in this area is complicated by general lack of quality control, use of many different species and strains and, above all, significant deficiencies in trial methodology $(18,19)$, especially for trials conducted before 2005 (20).

The recognition of an upregulated immune system response in the host suggests that an interaction between the host and gastrointestinal microbiota may be important in the pathogenesis of some functional gastrointestinal disorders (21). Immune activation has been widely emphasized in various unifying pathophysiological models to explain functional gastrointestinal disorders such as FB (10).

There is some evidence that inactivated bacterial products have immunological and functional properties both in vitro and in vivo (22-24). An oral mixture preparation of inactivated E. coli and E. faecalis (25) has been found effective for the treatment of abdominal symptoms due to IBS (26), even in randomized controlled trials (27). Also, other mixtures of different bacterial strains have been shown to be effective in functional gastrointestinal disorders $(28,29)$.

Other evidences show that the administration of the oral enterovaccine Colifagina ${ }^{\circledR}$ may be an effective oral immunostimulant, used in the treatment of colitis in experimental animal models (8).

The present study suggests that the same enterovaccine is able to improve FB without side effects. We want to stress that the study was carried out in patients with FB not associated with other gastrointestinal symptoms or diseases, such as IBS, as are most therapeutic studies on this topic (30). We hypothesized that the amelioration of symptoms in patients treated with this enterovaccine might be due to a modification of the intestinal flora toward strains sensitizing intestinal afferences to a lesser extent; however, as hypothesized in other studies with bacterial lysates (31), the enterovaccine itself might act via direct interaction with the immune system rather than via interaction with local bacteria.

Further data are obviously necessary to clarify these mechanisms.

We feel that this novel approach to a fastidious symptom might be worthwhile, since most alternative treatments are ineffective and the quality of life of these pa- tients may be improved to a great extent. Moreover, as reported for other interventions aimed at modifying the colonic flora, the lack of significant adverse events, high acceptance by patients, and clinical benefits reported may justify the use of such compounds, even though the intimate mechanisms of their mode of action are still unknown (32).

\section{REFERENCES}

1. Thompson WG, Irvine EJ, Pare P, Terrazzi S, Rance L. Functional gastrointestinal disorders in Canada: first population-based survey using the Rome II criteria with suggestion for improving the questionnaire. Dig Dis Sci 2002; 47: 225-35.

2. Chang L, Lee OY, Naliboff B, Schmulson M, Mayer EA. Sensation of bloating and visible abdominal distention in patients with irritable bowel syndrome. Am J Gastroenterol 2001; 96: 3341-7.

3. Sandler RS, Stewart WF, Lieberman JN, Ricci JA, Zorich NL. Abdominal pain, bloating, and diarrhea in the United States: prevalence and impact. Dig Dis Sci 2000; 45: 1166-71.

4. Talley NJ, Boyce P, Jones M. Identification of distinct upper and lower gastrointestinal symptom groupings in an urban population. Gut 1998; 42: 690-5

5. Longstreth GF, Thompson WG, Chey WD, Houghton LA, Mearin F, Spiller RC Functional bowel disorders. Gastroenterology 2006; 130: 1480-91.

6. Jiang X, Locke GR 3rd, Choung RS, Zinsmeister AR, Schleck CD, Talley NJ. Prevalence and risk factors for abdominal bloating and visible distention: a population-based study. Gut 2008; 57: 756-63.

7. Suarez FL, Furne J, Springfield J, Levitt MD. Failure of activated charcoal to reduce the release of gases produced by the colonic flora. Am J Gastroenterol 1999; 94: 208-12.

8. Vetrano S, Correale C, Borroni EM, Pagano N, Savino B, Locati M, et al. Colifagina, a novel preparation of 8 lysed bacteria ameliorates experimental colitis. Int J Immunopathol Pharmacol 2008; 21: 401-7.

9. Dughera L, Serra AM, Battaglia E, Tibaudi D, Navino M, Emanuelli G. Acute recurrent diverticulitis is prevented by oral administration of a polybacterial lysate suspension. Minerva Gastroenterol Dietol 2004; 50: 149-53.

10. Lin HC. Small intestinal bacterial overgrowth: a framework for understanding irritable bowel syndrome. JAMA 2004; 292: 852-8.

11. Lewis SJ, Heaton KW. Stool form scale as a useful guide to intestinal transit time. Scand J Gastroenterol 1997; 32: 920-4.

12. Schoeffer AM, Schaffer T, Seibold-Schmid B, Muller S, Seibold F. Antibodies to flagellin indicate reactivity to bacterial antigens in IBS patients. Neurogastroenterol Motil 2008; 20: 1110-8.

13. Whorwell PJ, Altringer L, Morel J, Bond Y, Charbonneau D, O'Mahony L, et al. Efficacy of an encapsulated probiotic Bifidobacterium infantis 35624 in women with irritable bowel syndrome. Am J Gastroenterol 2006; 101: 1581-90.

14. Fanigliulo L, Comparato G, Aragona G, Cavallaro L, Iori V, Maino $\mathrm{M}$, et al. Role of gut microflora and probiotic effects in the irritable bowel syndrome. Acta Biomed 2006; 77: 85-9.

15. Guyonnet D, Chassany O, Ducrotte P, Picard C, Mouret M, Mercier $\mathrm{CH}$, et al. Effect of a fermented milk containing Bifidobacterium animalis DN-173 010 on the health-related quality of life and symptoms in irritable bowel syndrome in adults in primary care: a multicentre, randomized, double-blind, controlled trial. Aliment Pharmacol Ther 2007; 26: 475-86.

16. Niedzielin K, Kordecki H, Birkenfeld B. A controlled, double-blind, randomized study on the efficacy of Lactobacillus plantarum $299 \mathrm{~V}$ in patients with irritable bowel syndrome. Eur J Gastroenterol Hepatol 2001; 13(10): 1143-7.

17. Agrawal A, Houghton LA, Morris J, Reilly B, Guyonnet D, Goupil Feuillerat N, et al. Clinical trial: the effects of a fermented milk product containing Bifidobacterium lactis DN-173-010 on abdominal distension and gastrointestinal transit in irritable bowel syndrome with 
constipation. Aliment Pharmacol Ther 2008; 29: 104-14.

18. Quigley EM. What is the evidence for the use of probiotics in functional disorders? Curr Gastroenterol Rep 2008; 10: 379-84.

19. Brenner DM, Moeller MJ, Chey WD, Schoenfeld PS. The utility of probiotics in the treatment of irritable bowel syndrome: a systematic review. Am J Gastroenterol 2009; 104: 1033-49.

20. Floch $\mathrm{MH}$. Use of diet and probiotic therapy in the irritable bowel syndrome: analysis of the literature. J Clin Gastroenterol 2005; 39(5 Supl. 3): S243-246.

21. Parkes GC, Brostoff J, Whelan K, Sanderson JD. Gastrointestinal microbiota in irritable bowel syndrome: their role in its pathogenesis and treatment. Am J Gastroenterol 2008; 103: 1557-67.

22. Verdú EF, Bercík P, Bergonzelli GE, Huang XX, Blennerhasset P, Rochat F, et al. Lactobacillus paracasei normalizes muscle hypercontractility in a murine model of postinfective gut dysfunction. Gastroenterology 2004; 127: 826-37.

23. Dehlink E, Domig KJ, Loibichler C, Kampl E, Eiwegger T, Georgopoulos A, et al. Heat- and formalin-inactivated probiotic bacteria induce comparable cytokine patterns in intestinal epithelial cell-leucocyte cocultures. J Food Prot 2007; 70: 2417-21.

24. Tsuchiya J, Barreto R, Okura R, Kawakita S, Fesce E, Marotta F Single-blind follow-up study on the effectiveness of a symbiotic preparation in irritable bowel syndrome. Chin J Dig Dis 2004; 5 : 169-74

25. Rusch V, Hyde RM, Ludley TD. Documentation of identify, production, harmelessness, efficacy, and durability of Symbioflor prepara- tions. Mikrookol Ther 1980; 10: 173-203.

26. Panijel M, Burkard I. Pro-symbioflor for treatment of the irritable colon. Jatros Nathurheilkunde 1993; 2: 1-4.

27. Enck P, Zimmermann K, Menke G, Müller-Lissner S, Martens U, Klosterhalfen S. A mixture of Escherichia coli (DSM 17252) and Enterococcus faecalis (DSM 16440) for treatment of the irritable bowel syndrome--a randomized controlled trial with primary care physicians. Neurogastroenterol Motil 2008; 20: 1103-9.

28. Kajander K, Hatakka K, Poussa T, Färkkilä M, Korpela R. A probiotic mixture alleviates symptoms in irritable bowel syndrome patients: a controlled 6-month intervention. Aliment Pharmacol Ther 2005; 22: 387-94.

29. Kim HJ, Vazquez Roque MI, Camilleri M, Stephens D, Burton DD, Baxter K, et al. A randomized controlled trial of a probiotic combination VSL\# 3 and placebo in irritable bowel syndrome with bloating. Neurogastroenterol Motil 2005; 17: 687-96.

30. Agrawal A, Whorwell P. Review article: abdominal bloating and distension in functional gastrointestinal disorders - epidemiology and exploration of possible mechanisms. Alim Pharmacol Ther 2008; 27: $2-10$

31. Kajander K, Krogius-Kurikka L, Rinttilä T, Karjalainen H, Palva A, Korpela R. Effects of multispecies probiotic supplementation on intestinal microbiota in irritable bowel syndrome. Aliment Pharmacol Ther 2007; 26: 463-73.

32. Shanahan F. Irritable bowel syndrome: shifting the focus towards the gut microbiota. Gastroenterology 2007; 133: 340-2. 